\title{
The Design of Data Collector to Calculate the Efficiency of DC to AC Inverter Based on ATmega328 and Micro SD as Storage Media
}

\author{
Kurnia Brahmana $^{1}$, Desse Mawarni Simatupang ${ }^{2}$ \\ ${ }^{1,2}$ Department of Physics, Faculty of Mathematics and Natural Science, Universitas Sumatera Utara, \\ Medan 20155, Indonesia
}

\begin{abstract}
The data collector to calculate the efficiency of the pure sine inverter DC to AC based on the level of efficiency, voltage and current stored automatically in Micro SD has been successfully designed. This data collector is built from the Arduino Nano (ATmega328) module as the controller and uses a Micro SD Card as a storage medium. The equipment storage results are displayed in real time using the RTC and LCD as a display medium for the measurement results of the voltage sensor and current sensor. The data logger is designed to be useful for storing data from the measurement results of the DC to AC inverter which consists of voltage, current and data collection time. The data every 16 seconds will be stored automatically on the Micro SD. The results of the reading error of the voltage sensor and current sensor are $1.088 \%$ and $1.72 \%$, respectively. The results of the error reading the voltage sensor and current sensor are still precise, so the efficiency obtained in this study is $78.37 \%$.
\end{abstract}

Keyword: Data Logger, Sensor, Inverter, Microcontroller.

Received 14 July 2020 | Revised [28 July 2020] | Accepted [27 August 2020]

\section{Introduction}

The development of research in the field of science and technology regarding the application of sensors and data logger systems has often been carried out, where the data collection process must be accurate to carry out analysis in the application of data recording systems. The electronic in-data recorder is a versatile device capable of obtaining data and storing data in non-volatile memory and data storage is carried out significantly [1]. A data recording system that is small, light, and low power is very important in an effective data recording system. The Secure Digital (SD) card is part of the Serial Peripheral Interface (SPI) module. The Trans Flash (TF) Mini card reader interface is compatible with Arduino and Secure Digital (SD) cards that can be operated with a power supply of $3 \mathrm{~V}$ or $5 \mathrm{~V}$ in DC conditions [2]. The Serial Peripheral Interface (SPI) module also has a built-in logic level shifter, so that the data interface

\footnotetext{
*Corresponding author at: Jalan Biolteknologi No.1 Medan, 20155, Indonesia

E-mail address: kurniabrahmana@usu.ac.id
} 
can be connected directly to the Arduino Uno board. The power measurement results have output in the form of voltage and current which will be stored directly in micro SD in real time. Data logger is designed and applied to save material and improve serial communication performance between internal components. The data logger is capable of operating micro SD memory with sizes up to $32 \mathrm{~GB}$ so that it will make human work easier.

Previous researchers have analyzed that the mobile data logger was developed using ArduinoUno. Several studies report that the mobile data logger is equipped with a GPS module that provides accurate positioning in data collection to record temperature, humidity and location coordinates. In addition, Andreola et al (2017) also explain that a data logger system based on a microcontroller (wind speed, wind direction, humidity and temperature) can cheaply store data on a Secure Digital (SD) memory card [3]. The same study was also delivered by Damanik et al (2019) where data that is compatible with Arduino can be designed for field research and stored on a micro SD card [4]. In today's technological developments, data storage components are needed that can present data in instant form with statistical treatment stored on cards that can be removed from electronic devices, and can be downloaded directly to a computer or transmitted remotely over a wireless network in real time or periodically such as micro SD memory. There are several basic types of flash memory cards available such as Compact Flash, Multi Media Card, Secure Digital Card [5]. Micro SD cards include a security-compliant copyright mechanism in the Serial Digital Interface (SDI) standard and can load data at a larger memory capacity [6]. The SD card is an easy-to-use data storage element in data loggers. Certain types of flash memory cards determine the $\mathrm{I} / \mathrm{O}$ pins on the microcontroller for establishing data communication. These types of cards are classified based on the form factor, namely standard $\mathrm{SD}$, mini SD, and micro SD. Micro SD is a memory that has a small energy consumption and the operating system is carried out via the SPI interface. The advantage of using a micro SD is that when the card goes into standby mode automatically and if no commands are received for 5 $\mathrm{ms}$ then this can potentially reduce power consumption [7].

Based on the literature review above, the author will make a study on the design of data collectors to calculate the efficiency of DC to AC inverters based on ATmega328 and Micro SD as data storage media. The type of Arduino used in this study is the Arduino Nano. Arduino Nano was chosen because of its ability to generate high frequency PWM and read analog inputs, its smaller size, and its relatively cheap price [8]. Arduino Nano as an implementation block of the Data Logger that regulates PWM, current and voltage data processing, data storage on Micro $\mathrm{SD}$, and data display on LCD. 


\section{Methods}

This data logger is designed with three main components, namely Arduino Nano as a data processor for sensors, ACS712 sensor as a voltage divider to read incoming currents, outflows, incoming voltages and output voltages, and Data Logger Shield to record data read by the ACS712 sensor.

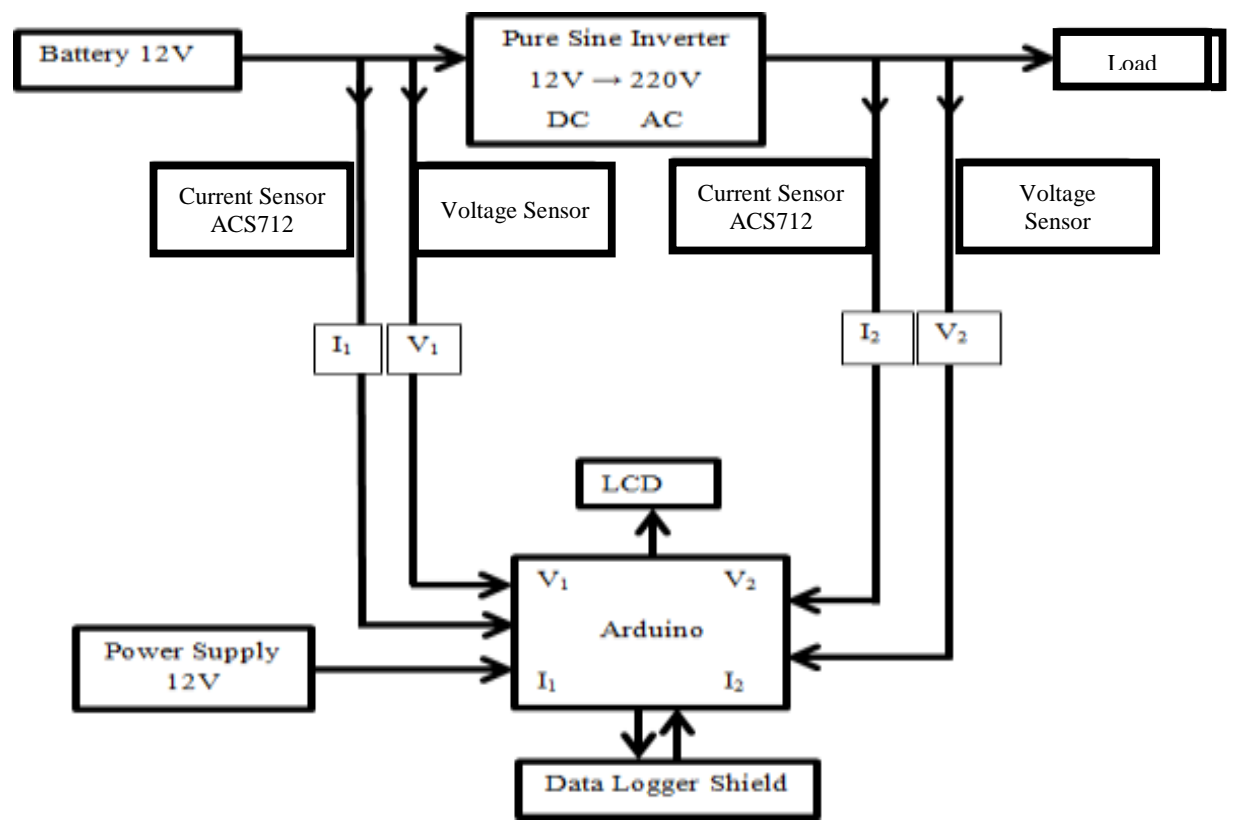

Figure 1. Block Diagram of the equipment

Figure 1 is a logger shield data block diagram of the structural design. The following is an explanation of the constituent components of Figure 1.

1. Block Battery $12 \mathrm{~V}$

: The voltage source runs the Object.

2. $12 \mathrm{~V}$ Power Supply

: Power source for Arduino, LCD, RTC, Micro SD, and Current / Voltage Sensor.

3. Block Current Sensor ACS712 : A sensor to measure the incoming and outgoing currents in the circuit Inverters.

4. Voltage Sensor Block : A sensor for measuring the inlet and outlet voltages on Inverter circuit.

5. Data Logger Shield Block : A data storage place for the I / O voltage and the I / O current that has been measured on the SD Card and is equipped with RTC (Real Time Clock) which is used to determine the time data is stored.

6. $16 \times 2$ LCD block : Display to display measured current and voltage.

7. Arduino block : Process the current and voltage sensor data from a 12 V battery and output 220V AC on the Inverter.

8. Block Pure Sine Inverter : The object to be measured is the efficiency parameter. 


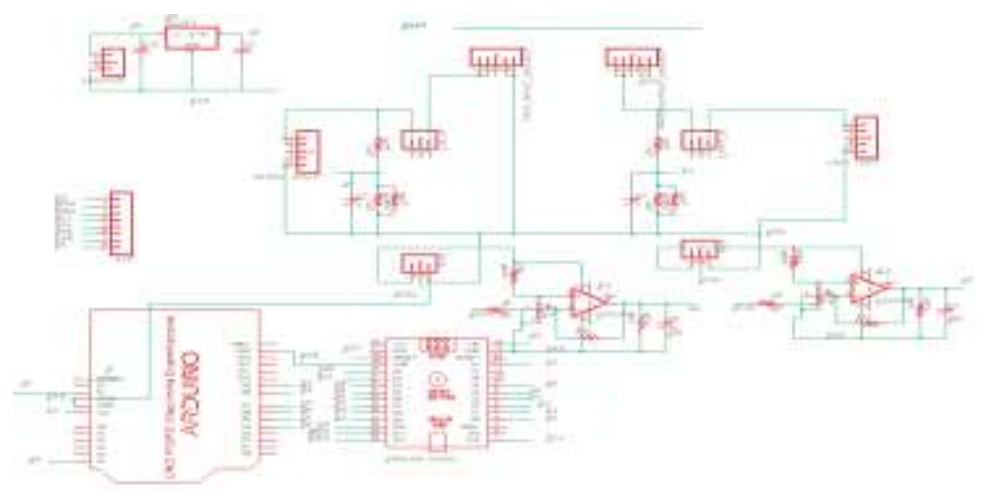

Figure 2. Test Logger Shield Data Series

The next design stage is to test the entire logger shield data series where the circuit is connected to the Arduino as shown in Figure 2. When the power from the $12 \mathrm{~V}$ battery flows to the object (Inverter), the Arduino will give PWM to the current sensor and voltage sensor, then the current sensor will measure I1 as the input current and the voltage sensor will measure V1 as the input voltage. Current sensors and voltage sensors will send the data that has been taken to the Arduino as programmed beforehand. Arduino will process the data so that it displays the data on the LCD in the format of date, month, year, hour, minute, V1 and I1 and saves it on the SD Card in the format of date, month, year, V1 and I1. Inverters that have operated to convert the DC current to $\mathrm{AC}$ will be re-measured by the current sensor $\mathrm{I} 2$ which will become the outflow and also measured by the voltage sensor V2 into the output voltage, then it will be reprocessed by Arduino. Furthermore, Arduino will send the data to the LCD and SD Card. Data retrieval is carried out repeatedly according to operator requirements. The data results from the logger shield data series in the form of data on incoming currents, incoming voltages, output currents and output voltages. This data will be used to calculate the efficiency of the invereter manually. 

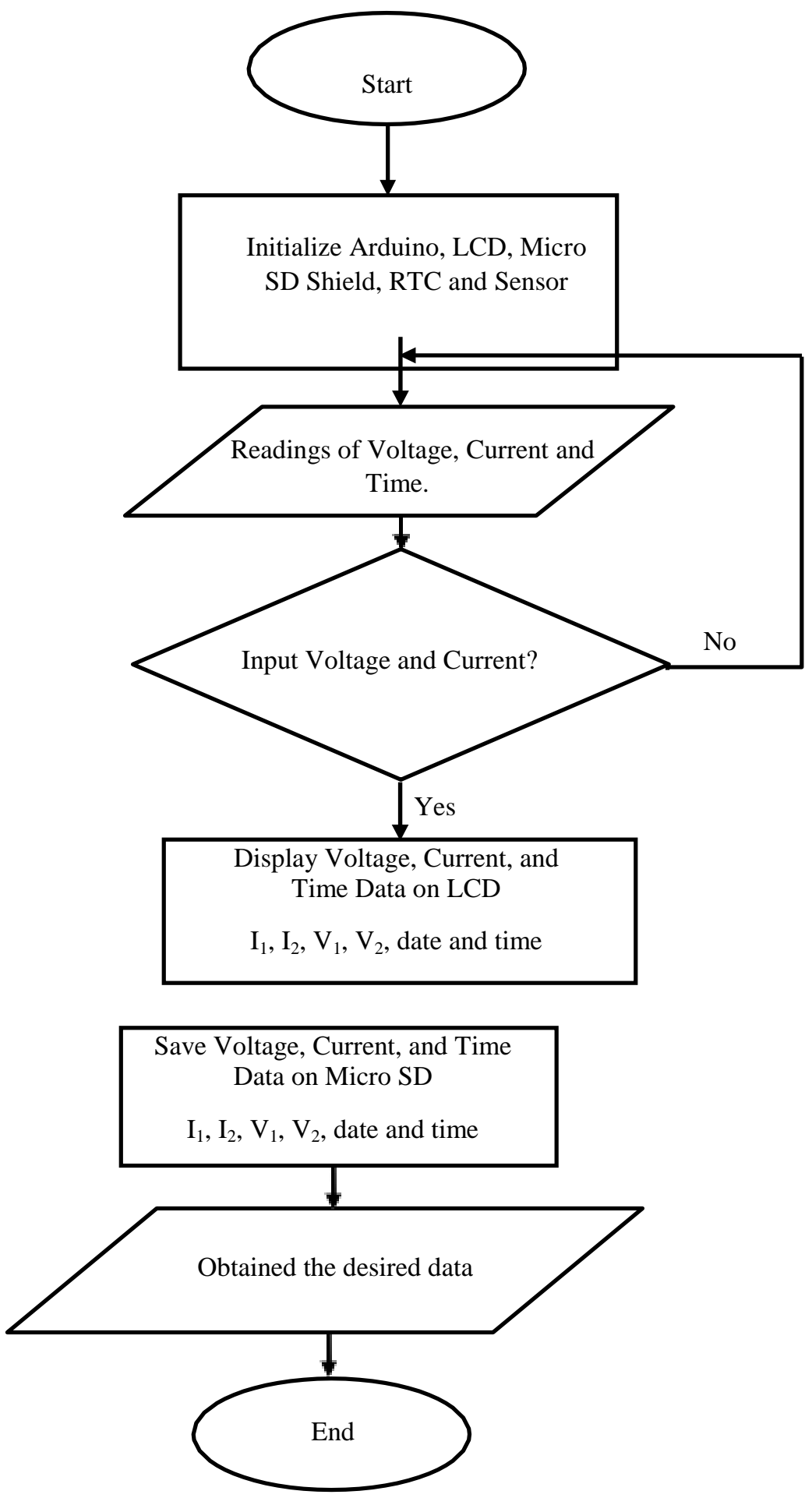

Figure 3. Flowchart of the equipment

\section{Result and Discussion}

The AC voltage sensor issues an analog signal where the reading by this sensor is carried out directly and received by Arduino via the ADC (Analog Digital Converter) pin. In this study, the components used are as follows pin $\mathrm{A} 1$ on the Arduino board, resistors $670 \mathrm{k} \Omega$ and $10 \mathrm{k} \Omega$ and a maximum detectable voltage of 340 volts. 
The analog value of the ACS712 sensor will change according to the current being flowed in the bias current in the logger shield data circuit [9-10]. If the ACS712 sensor is connected in a forward biased state according to pins + IP and -IP, the resulting analog value will increase, whereas if connected in a state of reverse bias current the resulting analog value will decrease. The current sensor in this study has a version of the ACS712-5A with a readable range of $-5 \mathrm{~A}$ to 5A. The ACS712-5A current sensor has $185 \mathrm{mV} / \mathrm{A}$ sensitivity and better resolution than other versions.

Data logger testing is carried out on a DC to AC Inverter with a load of 75 watts and 150 watts. In the process of recording sensor reading data, the SD Card module is connected to (Pin 13) SCLK, (Pin 12) MOSI, (Pin 11) MISO, and (Pin 10) CS. In this process, the Arduino module functions as an SPI Master and the SD card functions as an SPI Slave an (Pin 10) CS.

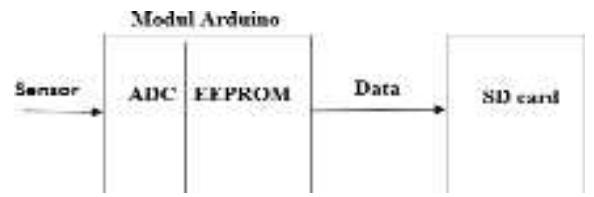

Figure 4. Data Reading Process to SD Card

Figure 4 shows a series of data reading processes to the SD Card. The current and voltage reading values from the sensor enter the analog pin in the form of a voltage parameter. Based on the results of the sensor readings obtained in the form of an analog, it will be converted into digital numbers by the ADC, then the value is entered into the eeprom then transferred to the SD card based on the command in the program listing. Tables 1 to 3 and Figures 4 to 7 are data and graph plots of data collection design tests to calculate the efficiency of a dc to ac inverter based on atmega328 and micro SD as data storage media.

Table 1 Testing Data Logger DC to AC Inverter with 75 Watt Load

\begin{tabular}{|c|c|c|c|c|c|c|}
\hline No & Time & $\begin{array}{c}V_{1} \\
\text { (Volt) }\end{array}$ & $\begin{array}{c}\mathbf{I}_{1} \\
\text { (Ampere) }\end{array}$ & $\begin{array}{c}\mathbf{V}_{2} \\
\text { (Volt) }\end{array}$ & $\begin{array}{c}\mathbf{I}_{2} \\
\text { (Amper } \\
\text { e) }\end{array}$ & $\eta_{(}(\%)$ \\
\hline 1 & 11:33:18 & 13.45 & 5.55 & 211.82 & 0.28 & 79.452 \\
\hline 2 & 11:33:19 & 13.48 & 5.52 & 211.75 & 0.28 & 79.680 \\
\hline 3 & $11: 33: 20$ & 13.44 & 5.50 & 211.88 & 0.27 & 77.391 \\
\hline 4 & $11: 33: 21$ & 13.48 & 5.51 & 211.67 & 0.28 & 79.795 \\
\hline 5 & $11: 33: 22$ & 13.43 & 5.60 & 211.4 & 0.29 & 81.515 \\
\hline 6 & $11: 33: 23$ & 13.42 & 5.00 & 211.98 & 0.25 & 78.979 \\
\hline 7 & $11: 33: 24$ & 13.46 & 5.38 & 211.8 & 0.27 & 78.970 \\
\hline 8 & $11: 33: 25$ & 13.44 & 5.30 & 211.85 & 0.27 & 80.300 \\
\hline 9 & $11: 33: 26$ & 13.49 & 5.48 & 211.52 & 0.28 & 80.115 \\
\hline 10 & $11: 33: 27$ & 13.42 & 5.46 & 211.85 & 0.27 & 78.063 \\
\hline 11 & $11: 33: 28$ & 13.44 & 5.48 & 211.4 & 0.28 & 80.368 \\
\hline 12 & $11: 33: 29$ & 13.45 & 5.38 & 211.62 & 0.27 & 78.961 \\
\hline 13 & $11: 33: 30$ & 13.48 & 5.50 & 211.7 & 0.28 & 79.951 \\
\hline 14 & $11: 33: 31$ & 13.42 & 5.40 & 211.73 & 0.27 & 78.885 \\
\hline 15 & $11: 33: 32$ & 13.40 & 5.56 & 211.7 & 0.28 & 79.560 \\
\hline \multirow[t]{2}{*}{16} & $11: 33: 32$ & 13.46 & 5.54 & 211.46 & 0.28 & 79.402 \\
\hline & & & Average & & & 79.462 \\
\hline
\end{tabular}




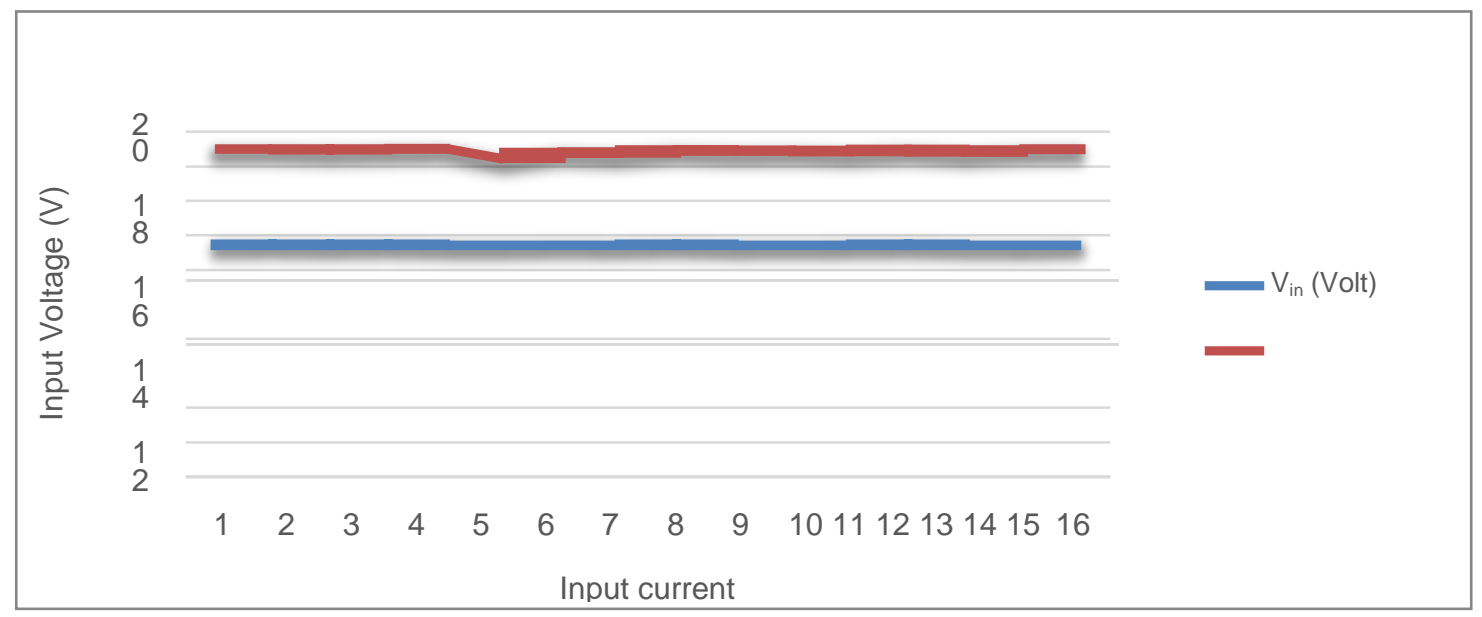

Figure 4. $V_{\text {in }}$ vs $I_{\text {in }}$ Graph for 75 Watt Load

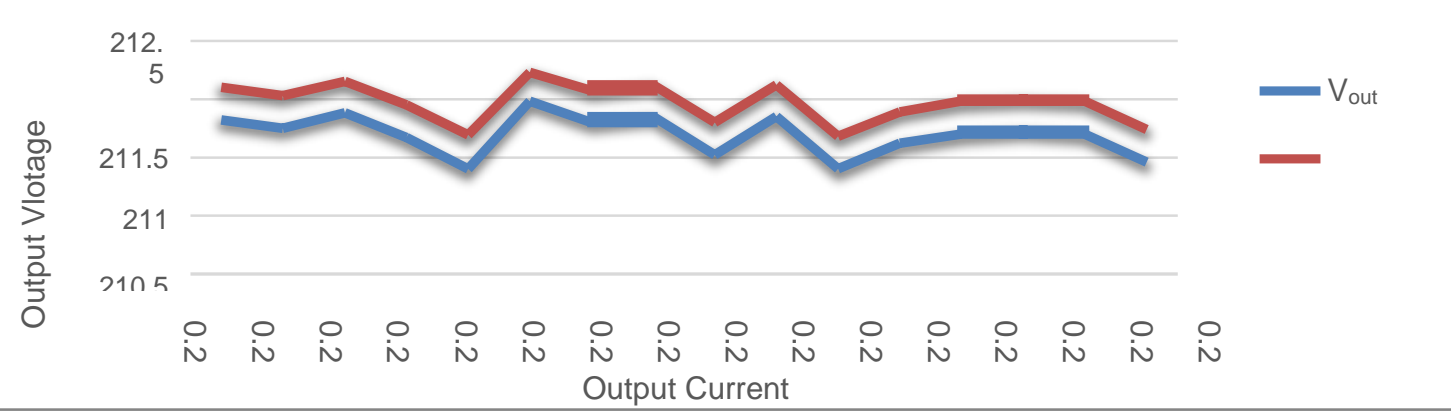

Figure 5. $\mathrm{V}_{\text {out }}$ vs $\mathrm{I}_{\text {out }}$ for 75 Watt Load

Table 2. Testing Data Logger DC to AC Inverter with 150 Watt Load

\begin{tabular}{|c|c|c|c|c|c|c|}
\hline No & Time & $\begin{array}{c}\mathrm{V}_{1} \\
\text { (Volt) }\end{array}$ & $\begin{array}{c}\mathbf{I}_{1} \\
\text { (Ampere) }\end{array}$ & $\begin{array}{c}V_{2} \\
\text { (Volt) }\end{array}$ & $\begin{array}{c}\mathbf{I}_{2} \\
\text { (Ampere) }\end{array}$ & n $(\%)$ \\
\hline 1 & 15:30:11 & 12.88 & 11.20 & 192.3 & 0.6 & 79.982 \\
\hline 2 & $15: 30: 12$ & 12.90 & 11.22 & 192.4 & 0.59 & 78.428 \\
\hline 3 & $15: 30: 13$ & 12.86 & 11.26 & 192.3 & 0.59 & 78.352 \\
\hline 4 & $15: 30: 14$ & 12.84 & 11.20 & 192.5 & 0.55 & 73.622 \\
\hline 5 & $15: 30: 15$ & 12.84 & 11.40 & 192.3 & 0.58 & 76.196 \\
\hline 6 & $15: 30: 16$ & 12.88 & 11.25 & 192.31 & 0.6 & 79.631 \\
\hline 7 & 15:30:17 & 12.90 & 11.26 & 192.6 & 0.6 & 79.557 \\
\hline 8 & $15: 30: 18$ & 12.84 & 11.20 & 192.21 & 0.57 & 76.184 \\
\hline 9 & $15: 30: 19$ & 12.83 & 11.20 & 192.32 & 0.56 & 74.949 \\
\hline 10 & $15: 30: 20$ & 12.88 & 11.18 & 192.33 & 0.58 & 77.467 \\
\hline 11 & $15: 30: 21$ & 12.90 & 11.20 & 192.4 & 0.55 & 73.241 \\
\hline 12 & $15: 30: 22$ & 12.92 & 11.25 & 192.45 & 0.6 & 79.442 \\
\hline 13 & $15: 30: 23$ & 12.90 & 11.18 & 192.4 & 0.58 & 77.375 \\
\hline 14 & $15: 30: 24$ & 12.80 & 11.16 & 192.42 & 0.58 & 78.127 \\
\hline 15 & $15: 30: 25$ & 12.84 & 11.22 & 192.3 & 0.57 & 76.084 \\
\hline 16 & $15: 30: 26$ & 12.81 & 11.16 & 192.5 & 0.58 & 78.098 \\
\hline \multicolumn{6}{|c|}{ Average } & 77.296 \\
\hline
\end{tabular}




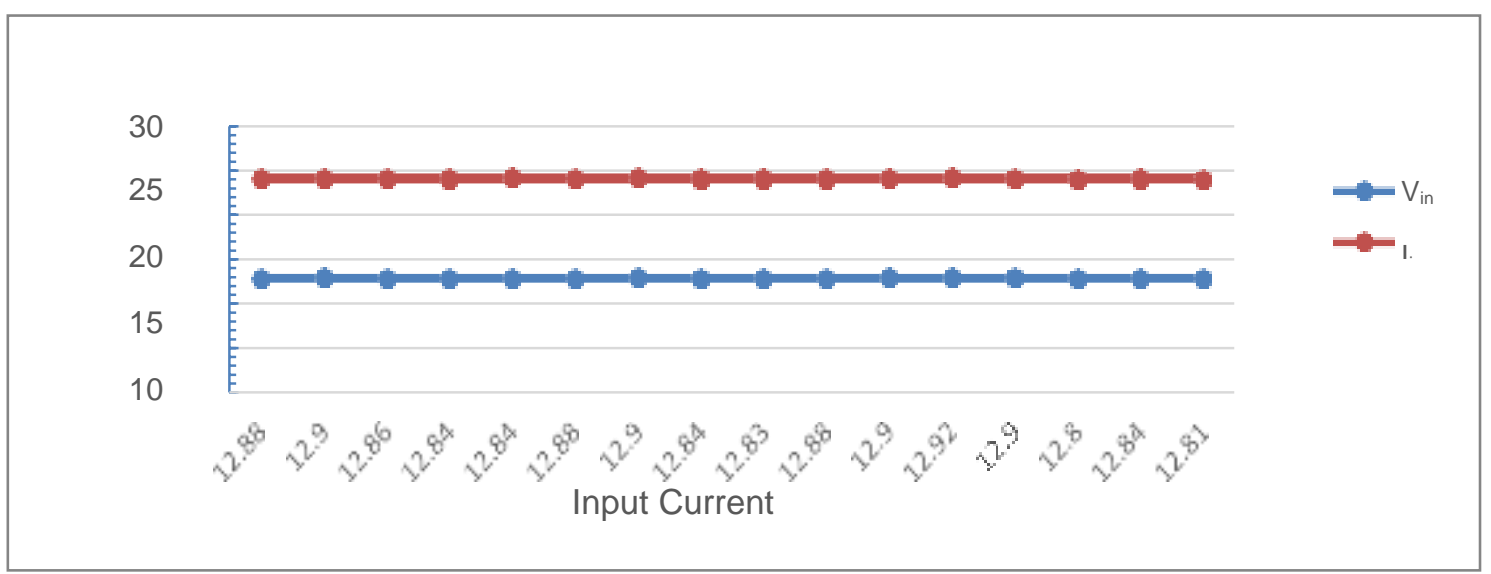

Figure 6. $\mathrm{V}_{\text {in }}$ vs $\mathrm{I}_{\text {in }}$ for 150 Watt Load

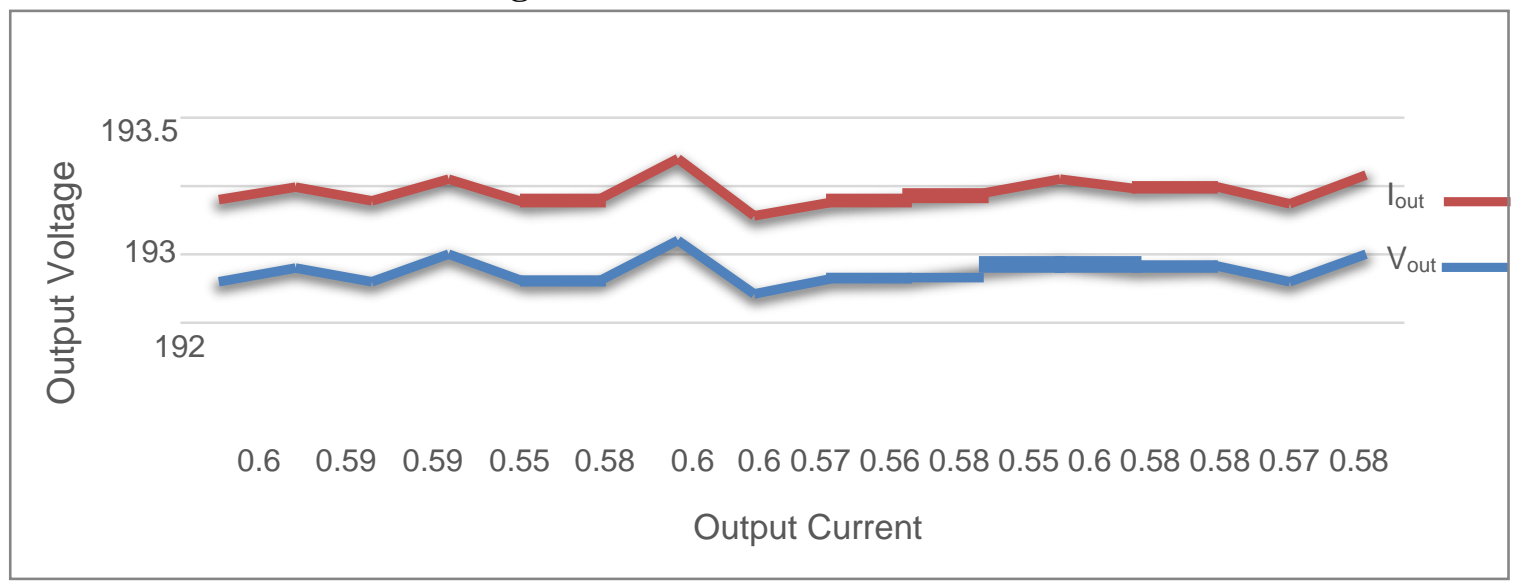

Figure 7. $\mathrm{V}_{\text {out }}$ vs $\mathrm{I}_{\text {out }}$ for $150 \mathrm{~W}$ att Load

From the data obtained, it can be concluded that the voltage is inversely proportional to the current and the load used. Then this situation can also be concluded that the higher the load used, the lower the voltage and the higher the current.

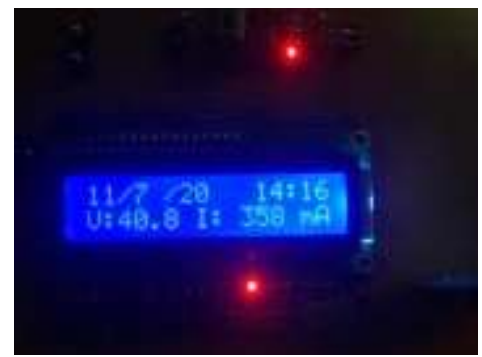

Figure 8. Logging Experiment of Data Shield on LCD

The efficiency of the DC to AC inverter can be found by calculating the ratio of the input power and output power to the DC to AC inverter using the equation.

Load with a power of 75 Watt can be averaged that the efficiency of the Pure Sine Inverter DC to AC with the input voltage from the Battery of 13.8 Volt is $79.46 \%$ so that it can be averaged over the efficiency of Pure Sine. DC to AC inverter at 150 Watt load with input voltage from 
Battery of 13.8 Volt is $77.29 \%$. So this situation can be stated that the efficiency of the Pure Sine DC to AC Inverter is $78.37 \%$.

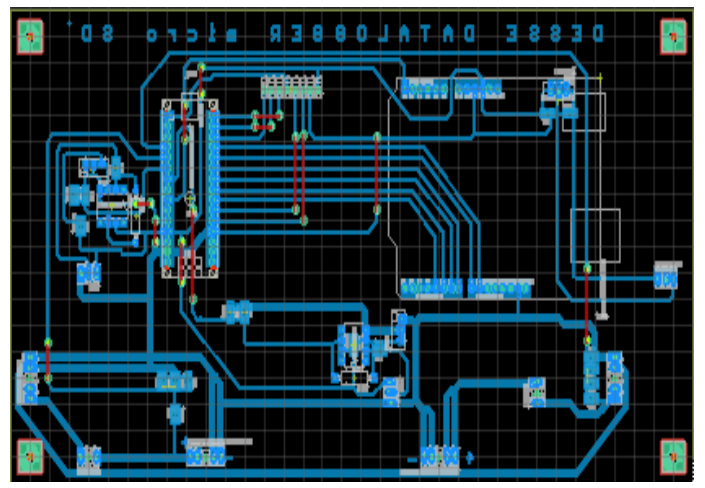

Figure 9. Network on the Eagle Board

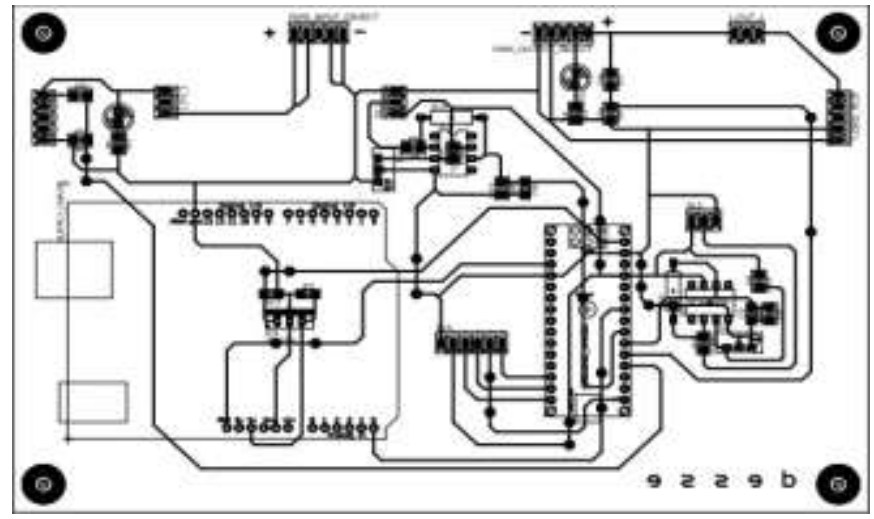

Figure 10. Network on PCB

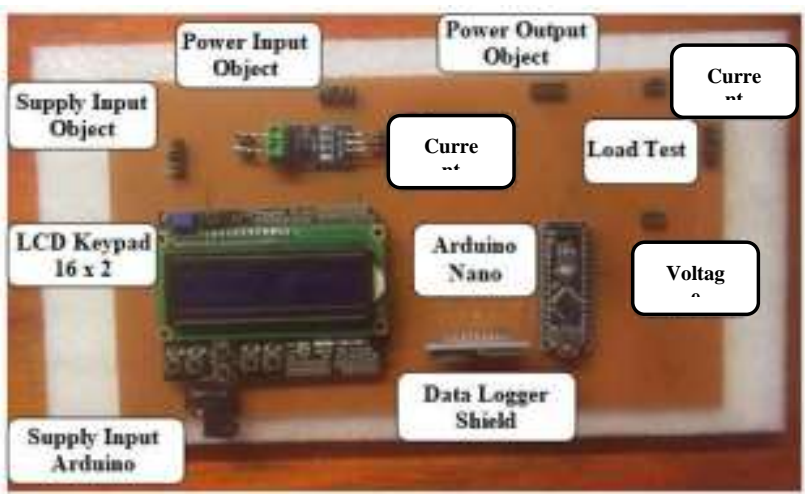

Figure 11. Data Logger Design 


\section{Conclusion}

After going through the design stage, testing and discussing the overall test results, several conclusions can be drawn that has succeeded in designing data collection tools. The instruction on programming resulted in a power efficiency of the DC to AC inverter of $78.37 \%$. Then the voltage sensor works well, where the error is $1.088 \%$ and the ACS712 module effectively reads the load current with an error of $1.72 \%$. The data logger design can be used to collect voltage and current data to calculate the power efficiency of the Pure Sine DC to AC inverter and the data that has been obtained can be recorded and stored properly on the Micro SD for a long time.

\section{REFERENCES}

[1] K.S. Immink, P. H. Siegel, and J. K. Wolf, "Codes for digital recorders", IEEE Transactions on Information Theory, Vol. 44, No.6, pp.2260-2299, 1998.

[2] J. Liu, and J. Liu, "Research of embedded Linux SD card device driver based on ARM", In 2012 International Conference on Control Engineering and Communication Technology, IEEE, pp. 33-36, 2012, December.

[3] A. T. Andreola, M. J. D. Senter, E. L. Todero, "Low Cost Data Acquisition System For Wind Prospecting", 2017.

[4] N. Damanik, M. R. Robiansyah, A. Apriliana, S. Purba, "Design of Energy Monitoring System for Small Scale Wind Turbine Applications", IOP Conference Series, 2019.

[5] А. В. Кушнір, Memory cards in our life (Doctoral dissertation, BНTУ), 2017.

[6] J. G. XU, J. ZHAO, W. LI, and J. TIAN, "Read and Write Operations of Micro SD Card Based on STM32F103XX Microcontroller [J]", Modern Electronics Technique, Vol. 20, 2010.

[7] N. Cameron, "SD Card Module" In Arduino Applied (pp. 219-236). Apress, Berkeley, CA, 2019.

[8] A. Nano, Arduino Nano, 2018.

[9] L. Li, Y. Chen, Y. and J. Liu, "The application of hall sensors ACS712 in the protection circuit of controller for humanoid robots", In 2010 International Conference on Computer Application and System Modeling (ICCASM 2010), IEEE, Vol. 12, pp. V12-101, 2010, October.

[10] U. Khair, A. J. Lubis, I. Agustha, and M. Zulfin, "Modeling and simulation of electrical prevenion system using Arduino Uno, GSM modem, and ACS712 current sensor", In Journal of Physics: Conference Series, Vol. 930, No. 1, p. 012049, 2017, December. 